\title{
Capítulo 2 \\ La construcción legislativa y judicial de la paz colombiana: "Una política que silencia el perdón”
}

\author{
Andrea Paola Buitrago Rojas
}

En Colombia, las políticas de reparación a las víctimas, desde la figura del perdón, se desarrollan a través de la Ley de Justicia y Paz, la cual, por primera vez en la historia de nuestro país, sentó un precedente normativo en torno a la importancia ética y política de la petición de perdón a las víctimas. La investigación que ha dado lugar al presente texto, analiza las dimensiones y lineamientos éticos del perdón, una vez se le sitúa en el marco público-político y especialmente en el marco de la mencionada ley. Posteriormente, analiza los discursos de los versionados de la Ley de Justicia y Paz para comprender el contenido argumentativo y retórico que despliegan los victimarios en torno al perdón. Finalmente, estudia la realización de los discursos en torno al perdón, a la luz de los criterios éticos del perdón mismo.

El presente capítulo desarrolla una reconstrucción de la Ley 975 de 2005, tomando sus antecedentes internacionales en la Justicia Transicional desde la propuesta de Ruti Teilet, los proyectos de ley que consolidaron la legislación, algunas intervenciones realizadas durante la aprobación, la sentencia de la Corte Constitucional que determina la exequibilidad 
de la norma a partir del juicio de proporcionalidad entre paz y justicia. Y finalmente, los avances legislativos que se han dado alrededor de la materia, examinando la introducción y determinación de tres tipos de perdón que la legislación legitima: Estado-victimario, victimario-víctima, victimario-sociedad, para así evidenciar los problemas éticos que su aplicación genera tomando a manera de ejemplo la petición de perdón realizada por el exlíder paramilitar Salvatore Mancuso.

Generar una reconstrucción de la figura del perdón al interior del marco jurídico y político en Colombia, lleva a ubicar el proceso de paz dentro de un contexto histórico que refleja la inexistencia del denominado postconflicto. No obstante, se han desarrollado procesos de diálogos con grupos al margen de la ley, es el caso de los grupos paramilitares y en la actualidad de las FARC, lo cual ha generado la implementación jurídica de la Justicia Transicional; desconceptualizando su naturaleza teórica, ya que ésta se concibe como un tipo de justicia que se aplica en un periodo de transición de la guerra a la paz, de una dictadura a una democracia, reorganizando a la sociedad:

Esta situación no deja de ser paradójica pues, aunque no existe una definición de Justicia Transicional unánimemente aceptada por los estudiosos, es claro que ésta hace al menos referencia a la siguiente idea: que las transiciones de la guerra a la paz o de las dictaduras a las democracias deben respetar unos estándares mínimos de justicia, que están vinculados a los derechos de las víctimas de los crímenes atroces. Por consiguiente, para hablar de Justicia Transicional, parecería sería necesario que al menos Colombia estuviera viviendo realmente una transición, esto es una superación del conflicto armado. Pero, como lo veremos, eso dista de ser así, pues en el mejor de los casos, la desmovilización de los grupos paramilitares sería una transición únicamente parcial, pues no involucra a todos los actores armados ilegales. (Uprimmy \& Safon, 2008, p. 1)

Esta situación ha generado un debate político, jurídico y filosófico en relación con el perdón en Colombia desde tres perspectivas: la primera, el perdón realizado por el Estado en la imposición y/o rebaja de penas a los actores del conflicto armado que deciden acceder 
al proceso de reintegración social, la segunda, el perdón derivado de la obligación que tiene el Estado colombiano con la población civil y la comunidad internacional de pedir excusas públicas por la acción y/o omisión de su actividad pública, que ha generado graves consecuencias como son las violaciones a los derechos humanos y la infracción a las normas del Derecho Internacional Humanitario, y la tercera, el perdón establecido en la Ley 975 de 2005 como elemento de la reparación simbólica, que tiene por destinatario a los grupos desmovilizados, al introducir la obligación de pedir perdón, en las relaciones interpersonales derivadas entre los victimarios y las víctimas.

\section{Antecedentes internacionales de la Ley de Justicia y Paz}

Ruti G. Teitel (2003) en su artículo "Genealogía de la Justicia Transicional”, expresa que el concepto de Justicia Transicional representa la ubicación de un periodo de cambio político, cuyo principal objetivo es enfrentar los crímenes que han sido cometidos por regímenes de represión. Una genealogía, según expresa Teitel, debe comprender un examen de periodos de cambio político, lo cual puede generar un ejercicio de gran amplitud, por lo que tomará como límite temporal el siglo XX. La construcción de la Justicia Transicional persigue en el discurso vigente el mantenimiento o consolidación de la paz democrática, por lo que pueden ubicarse tres fases: la primera entre el período de la Primera Guerra Mundial y el periodo de la posguerra de 1945, la segunda a finales del siglo XX y la tercera, una contemporánea.

En la primera fase se ubica el tribunal de Núremberg que entró en cooperación con los distintos estados a fin de generar un proceso común de sanción, reproche y rechazo de la guerra, por lo que se habla de un periodo de posguerra. A pesar de no existir el concepto de Justicia Transicional pueden evidenciarse sus rasgos principales en la búsqueda o transición hacia un nuevo orden político, después de un periodo de represión o conflicto.

Al menos dos respuestas críticas emergen respecto a la Justicia Transicional de la Segunda Guerra Mundial. Primero, la justicia 
nacional fue desplazada en favor de la justicia internacional. La administración del modelo de Justicia Transicional punitiva del período post Primera Guerra Mundial, caracterizada por fallidos juicios nacionales, fue dejada en manos de Alemania. Visto con retrospectiva histórica, parecía bastante claro que los juicios nacionales del período post Primera Guerra Mundial no sirvieron para evitar la futura matanza ocurrida en la Segunda Guerra Mundial. En una evidente respuesta crítica al pasado, la Justicia Transicional del período post Segunda Guerra Mundial comenzó por evitar procesamientos a nivel nacional. En cambio, se buscó la responsabilidad criminal del liderazgo del Reich a nivel internacional. La segunda respuesta crítica se refiere a las sanciones colectivas impuestas a Alemania a partir del fin de la Primera Guerra Mundial. Visto desde la perspectiva de la genealogía, estas respuestas transicionales claramente fracasaron y vinieron a identificarse como la base para el surgimiento de un sentido de frustración económica y resentimiento que impulsó el rol de Alemania en la Segunda Guerra Mundial. Las onerosas sanciones impuestas y sus crudas consecuencias - que además no discriminaban entre individuos, hicieron surgir interrogantes normativas profundas. Este abordaje dio cabida a la respuesta crítica que siguió a la Segunda Guerra Mundial y al enfoque más liberal de enjuiciamiento en base a las responsabilidades individuales. (Teitel, 2003, pp. 4-5)

La segunda fase se caracterizó por un periodo de aceleración en la resolución de conflictos y por la consolidación del discurso de la justicia mundial, del Derecho y su relación con la sociedad. Allí se ubicó una etapa de "equilibrio bipolar" caracterizada por la constante búsqueda de mantener el statu quo del sistema capitalista, como consecuencia de la reintegración de la Unión de Repúblicas Socialistas Soviéticas ligadas a la construcción y consolidación de las guerrillas en América Latina a finales de la década de los setentas, cuya consecuencia política fue el surgimiento de los regímenes militares en el Continente.

En 1989, se generaron periodos de transición bajo la idea de una reconstrucción del tejido social mediante las Comisiones de Verdad y Justicia, caracterizadas por desarrollar el vínculo entre la Justicia 
Transicional y el contexto político; se implementó un modelo de justicia restaurativa, cuya principal finalidad fue la reconstrucción histórica de la violencia del pasado; que acentuaba la disyuntiva verdad-justicia.

El modelo de la fase II pareció impulsar algunos de los objetivos de la justicia criminal del estado de derecho en sociedades en transición, en las cuales las instituciones legales funcionaban bajo condiciones de tensión transicional. Visto desde una perspectiva genealógica, el objetivo primordial de las comisiones de verdad no era la verdad, sino la paz. Esto planteó la interrogante sobre la relación esperada entre la paz y la promoción del estado de derecho y la democracia (...). No obstante, a menudo los propósitos de una Comisión de Verdad se consideran análogos a aquellos de la justicia criminal, ya que tanto los procesos judiciales como las comisiones de verdad pueden entenderse como animados fundamentalmente por la idea de la disuasión. De hecho, los mandatos de tales comisiones frecuentemente incluyen recomendaciones para prevenir la recurrencia de los abusos a los derechos humanos. (Teitel, 2003, p. 2)

Lo significativo de las comisiones de verdad es que permiten el desarrollo de una reconstrucción histórica por fuera del estudio de casos individuales y aislados, ya que persiguen una reconstrucción del contexto político que viabilizó la violación a los derechos humanos. Este desarrollo institucional generó la discusión entre paz y democracia, sobre su orden cronológico y su relación en la reconstrucción de la verdad, punto en el que se estimó el paso de una justicia particular a una justicia en la reconciliación de las víctimas y la reacreditación social de las instituciones públicas.

La reconstrucción de la identidad por fuera del ámbito jurídico, expresa Teitel, implicó una reflexión desde la Ética, la Medicina y la Teología al abordar el concepto de paz como problema de la Justicia Transicional en la redefinición de la identidad de las víctimas al interior de la reflexión universal del perdón y la reconciliación.

El tipo de derecho que se propició presenta un lenguaje universalizador acerca de los objetivos del perdón y la posibilidad de 
redención política. Mientras el derecho, como se entiende convencionalmente, prácticamente desapareció, se dijo que el modelo alternativo tenía aplicación universal y se aseguraba que podría ser difundido en todo el mundo. Considérese el grado en que se está exportando la Justicia Transicional en el paradigma de la posguerra fría como una religión secularizada y sin ley (...). Sin embargo, este tipo de políticas de reconciliación pueden perfectamente acarrear consecuencias negativas en el largo plazo. Por ejemplo, la incitación a llegar a acuerdos sobre los reclamos por actos del pasado puede tener ramificaciones conservadoras. Tal enfoque puede socavar reformas políticas más amplias y en general puede que no ayude a echar las bases para el desarrollo de la democracia. (Teitel, 2003, p. 15)

La tercera fase se genera a finales del siglo XX y comienzos del XXI y se distingue por la aceleración conceptual y práctica de la Justicia Transicional en el marco de la globalización, las condiciones marcadas de violencia y la inestabilidad política, referidas bajo la legitimación de la categoría del terrorismo, por lo que aparece la posibilidad de la autodefensa y con ella, la guerra permanente:

La normalización de la Justicia Transicional actualmente toma la forma de la expansión del Derecho de la Guerra, como lo ilustra el incremento en la importancia del Derecho Humanitario. Los acontecimientos contemporáneos implican una apropiación del discurso del Derecho Humanitario con un doble significado. El establecimiento del Derecho Humanitario como el estado de derecho del presente restringe no sólo la forma en que se conduce la guerra, sino que también parece expandir el sistema humanitario para responder a aspectos más amplios del Derecho de la Guerra, incluyendo la justificación de su posible iniciación. (...) Ya sea unilateral o multilateralmente, el expandido Derecho Humanitario permite la identificación de fallas en la acción del Estado, pero también parece presionar para que el Estado cumpla con los derechos humanos. Esto demuestra el potencial para deslizarse desde una Justicia Transicional normalizada hacia la campaña en contra del terrorismo. (Teitel, 2003, p. 24). 
En este contexto, afirma el autor que la normalización de una Justicia Transicional ha generado un discurso articulado al Derecho de Guerra y los Derechos Humanos, mostrando la correspondencia de una Justicia Transicional con la consolidación de presupuestos jurídico políticos que permiten expresar un contexto de cambio, más allá de un periodo de transición, al desplegar un marco estatal en la legitimación interna del Estado.

\section{Desarrollo legislativo y judicial de la Ley de Justicia y Paz en Colombia}

La Ley 975 de 2005 (julio 25) Diario Oficial N. ${ }^{\circ} 45.980$ de 25 de julio de 2005 tiene como antecedentes los debates generados alrededor de los distintos proyectos legislativos que contribuyeron a su consolidación: 180 de 2004, 208 de 2005, 209 de 2005, 210 de 2005, 211 de 2005 y 212 de 2005, de los cuales se realizará un breve examen del contenido normativo a fin de determinar una interpretación óptima sobre el sentido de la norma y la regulación del perdón. Posteriormente, se examinará la sentencia que determinó su exequibilidad constitucional, con algunos avances normativos que regularon la materia de estudio.

Dentro de los proyectos legislativos, se encuentra el número 180 de 2004 del Senado "Por la cual se dictan normas sobre Verdad, Justicia, Reparación, Prevención, Publicidad y Memoria para el sometimiento de los grupos”, propuesto por la senadora Piedad Córdoba al formular la necesidad de desarrollar un marco legal en materia de verdad y memoria, atendiendo la consolidación de estructuras punibles donde se reconozca la responsabilidad del Estado en el contexto de violencia que ha sufrido la población, específicamente en la consolidación de grupos paramilitares, por lo cual dicha política debe reconocer el llamado de la víctimas y del pueblo colombiano por los crímenes cometidos contra la población civil:

Considero que otros proyectos de ley anteriores buscan el esclarecimiento profundo de los crímenes de lesa humanidad y de guerra cometidos por el paramilitarismo. No establecen el origen de este fenómeno como una política de Estado, ni dotan a dichos 
proyectos de los mecanismos idóneos para el esclarecimiento. No proponen una Comisión de la Verdad, dejando a unidades de la Fiscalía la labor que debe cumplir la sociedad civil con apoyo de las víctimas, desde una auténtica Comisión de la Verdad, única que puede esclarecer los hechos históricos y a la vez acompañar un proceso de pedagogía social y de reflexión ética colectiva, que concite la participación de los más diversos sectores de nuestra sociedad, los cuales asuman esta verdad y adopten las actitudes y acciones necesarias para curar las profundas heridas causadas al país por las violaciones a los derechos humanos. Si reconstruir la verdad es una ardua tarea para esta comisión mixta, nacional e internacional, emplearla para la reconciliación nacional es un delicado y fundamental deber de todos los colombianos y colombianas. (Proyecto de Ley 180 de 2004)

El Proyecto de Ley 208 de 2005 del Senado "por la cual se dictan disposiciones para la reincorporación de miembros de grupos armados organizados al margen de la ley que contribuyan de manera efectiva a la consecución de la paz nacional”, es un avance normativo que expresa la postura de los senadores Rafael Pardo Rueda, Andrés González Díaz, Luis Fernando Velasco, Gina Parody D’Echeona, Wilson Borja Díaz y representantes a la Cámara, Gustavo Petro Urrego, Venus Albeiro Silva Gómez; y la de los partidos políticos: Polo Democrático, Alternativa Democrática, Partido Liberal Colombiano y Nueva Fuerza Democrática. Se rememora el desarrollo de la Ley de Alternatividad penal del 23 de octubre de 2003 y sus posteriores audiencias del 4 de febrero de 2005, donde se consolidó un proceso que permitiera superar el fenómeno del paramilitarismo requerido por la Comisión de Paz de la Presidencia de la República, donde se perseguía la construcción de un marco jurídico de negociación que contuviera medidas de Justicia Transicional que reconozcan la participación social.

Este derecho tiene, como contrapartida, un "deber de la memoria" a cargo del Estado, pues, como lo afirma Joinet, "el conocimiento, para un pueblo, de la historia de su opresión pertenece a su 
patrimonio y como tal debe ser preservado”. (...) Este derecho supone que las víctimas puedan acceder a un recurso eficaz para garantizar la reparación integral de los perjuicios sufridos, a través de tres tipos de medidas: (1) la restitución de las cosas a su estado anterior; (2) la indemnización de los perjuicios materiales y morales, y (3) la adecuada readaptación de las víctimas, mediante atención psicológica y psiquiátrica. En el plano colectivo, por su parte, se deben adoptar medidas de reparación dirigidas a restaurar, indemnizar o readaptar los derechos de las colectividades o comunidades directamente afectadas. Adicionalmente, la reparación individual o colectiva puede ser simbólica. Esta incluye el reconocimiento público y solemne que los culpables hacen de su responsabilidad, así como ceremonias conmemorativas, denominaciones de vías públicas, monumentos, y otras alternativas que permiten asumir el deber de la memoria. (Copia del Proyecto de Ley 208 de 2005)

La administración de justicia como deber del Estado se justifica en la necesidad de desarrollar investigaciones claras, precisas y oportunas con los fenómenos de macrocriminalidad vivenciados en la población colombiana, por lo que la construcción legal de un marco de Justicia Transicional exige el desarrollo de una justicia alternativa que permita el ejercicio del perdón como mecanismo que posibilite la realización de una investigación judicial integral de los hechos de violencia, cuyo requisito es la generación de una libertad condicional a los agresores. A este marco se le incluye la función de cooperación de la confesión seria y responsable de los delitos por parte de los victimarios que tuvieron una participación o coparticipación en la estructura criminal, según lo expresan los proponentes de la ley.

Esta reconstrucción de verdad atendería a la fundamentación histórico-política que han tenido las comisiones de la Verdad, donde la consolidación de las garantías para su ejecución, constituye uno de sus elementos característicos, a fin de evitar la generación de riesgos y/o amenazas a los derechos de las víctimas, victimarios y miembros de la comisión, que implican una obstaculización de su finalidad primordial: la obtención efectiva de la verdad. El perdón se sitúa dentro de una narrativa que lo comprende en la relación, sociedad-victimario, cuya 
justificación aparece en la consolidación de la paz en la sociedad, sin que por ello quiera significar el sacrificio de los derechos de las víctimas:

Un asunto es el perdón por los crímenes políticos cometidos, y otro bien distinto el sacrificio injusto e innecesario de los derechos de las víctimas a la verdad y la reparación. En este sentido, no sobra recordar que la Corte Constitucional, en reiterada jurisprudencia, ha sostenido que las víctimas de violaciones a los derechos humanos tienen derecho constitucional fundamental a la verdad, la justicia y la reparación. (...) En efecto, como se ha reiterado en la jurisprudencia nacional e internacional, la impunidad no sólo puede producirse porque exista una ley que perdone lo imperdonable, sino también porque el Estado deje de adelantar las mínimas labores de investigación necesarias para identificar a los responsables de estos crímenes. (...) En este proceso de restablecimiento de equilibrios, es necesario reconocer la dignidad de las víctimas, pedirles perdón por lo que se hizo o lo que se dejó de hacer para protegerlas, restituirles sus bienes, apoyarlas a través de programas psicosociales y, lo que es quizás más importante, devolverles la confianza en el Estado.

(Copia del Proyecto de Ley 208 de 2005)

Durante el año 2005, se consolidó el proyecto legislativo número 209 de 2005, denominado: "Por la cual se establecen las condiciones y procedimientos para la devolución y restitución de bienes entregados por parte de grupos desmovilizados en los procesos de paz", propuesto por el senador de la república Carlos Moreno de Caro, quien propuso la necesidad de generar una política de restitución de tierras vinculado al proceso de Justicia Transicional que se intentaba desarrollar al interior de la ley, ya que la construcción de un escenario de desmovilización comprende la ubicación de los bienes que han sufrido modificaciones en alguno de los atributos legales de la propiedad y que a su vez tienen un lugar relevante en la reparación integral de las víctimas.

Durante el mismo año se desarrolló un tercer proyecto (210 de 2005) "Por la paz y la reconciliación nacional (reparación y rehabilitación)”. Formulado por el senador Ricardo Español Suárez, quien a partir 
de un recorrido histórico de los antecedentes del conflicto armado en Colombia durante los años 40 y 50, nos permite recordar los distintos escenarios de reconciliación nacional; es el caso específico de la Ley de Amnistía generada por el expresidente Lleras Camargo, a favor de las autodefensas campesinas organizadas en repúblicas independientes del Pato, Guayabero, Riochiquito y Marquetalia. Evoca el senador que a inicios de la década de los 80 el Estado colombiano desarrolló una política de represión cuyo efecto fue el fortalecimiento de frentes guerrilleros, lo que condujo a una posterior reforma legal que comprendía la creación de una ley de amnistía durante los procesos de concertación con organizaciones guerrilleras. Este proceso culminó con la masacre del Palacio de Justicia. Posteriormente, aparece la desmovilización del M-19 (Movimiento 19 de abril) que dio origen a la Constituyente de 1991, sin conseguir la desmovilización total de los grupos guerrilleros que existían en el país en ese momento. Argumenta el senador que uno de los detonantes que justificaron la dificultad del diálogo fue la renuncia por parte del Gobierno y la aplicación de la política de la "mano dura", sin alcanzar acuerdo alguno que causara la vía de la paz para el país.

Un cuarto proyecto que tuvo lugar en el 2005, fue el número 211 de 2005 del Senado "Ley de Justicia y Paz efectiva a la consecución de la paz nacional por la cual se dictan disposiciones para la reincorporación de miembros de grupos armados organizados al margen de la ley, que contribuyan de manera efectiva a la consecución de la paz nacional”, fue expuesto por el ministro del interior y de justicia, el Dr. Sabas Pretelt de la Vega, quien afirmó una defensa de la Ley de Amnistía e Indulto; rememorando los procesos de paz con "el M-19, el Quintín Lame, el EPL, la Corriente de Renovación Socialista, como en las desmovilizaciones individuales que han tenido lugar hasta la fecha".

Aparece la figura del perdón judicial en la relación, Estadovictimario; se delimita a aquellos que cometieron un hecho criminal desde una organización insurgente, alzada en armas. Para el ministro estos elementos constituyen hechos históricos que reflejan la necesidad de dar continuidad a la Ley 782 de 2002 en materia de indulto o amnistía, sobre la comisión de delitos políticos; en el caso de aquellos que efectuaron delitos de otra índole siendo partícipes de este tipo de organizaciones se le debería dar aplicación judicial acorde con la Ley de verdad, 
justicia y reparación (la cual se hallaba en construcción), a fin de lograr la reconciliación nacional (Copia del Proyecto de Ley 211 de 2005):

La paz es el gran propósito nacional. La Constitución de 1991 la concibe como el objetivo central del Estado Social de Derecho. La política de seguridad democrática adelantada por el Gobierno Nacional no tiene propósito distinto que alcanzar la paz combinando con precisión el uso legítimo de la fuerza y la vía dialogada. Ahora bien: No puede ponerse en duda que a esta ley sólo podrán acogerse quienes hayan demostrado su voluntad de paz y sólo (sic) respecto de los hechos cometidos con ocasión de la pertenencia al grupo armado ilegal y con anterioridad a la promulgación de la presente normatividad. En cuanto hace referencia a la vigencia de esta ley, se ha considerado inoportuno el establecimiento de plazos y se propone en cambio que su tiempo de duración quede abierto, para enviar así un doble mensaje a los miembros de grupos armados ilegales: en primer término, que a partir de la fecha de su promulgación no pueden volver a delinquir, so pena de quedar por fuera de los efectos de esta; y en segundo lugar, que la oportunidad de desmovilizarse se mantiene abierta y de manera generosa para que tanto las FARC, el ELN y los grupos de Autodefensas se acojan a un proceso de reconciliación nacional que tanto desean los colombianos (...). (Copia del Proyecto de Ley 211 de 2005)

El último proyecto de ley de ese año fue el número 212 de 2005, denominado "Por medio de la cual se dictan disposiciones tendientes a la desmovilización de grupos armados y búsqueda de la reconciliación nacional", presentado por los congresistas: Sandra Ceballos, Omar Flórez, Adriana Gutiérrez, William Vélez, Zulema Jattin, Carlos Ignacio Cuervo, Armando Benedetti y Eduardo Crissien, quienes expresaron de manera conjunta que la consolidación de la ley tiene como finalidad primordial la reconciliación nacional y la eliminación de escenarios que propicien la comisión de delitos futuros. Plantean una cordial invitación, aceptada, a los grupos armados ilegales, específicamente a las FARC, el ELN y las AUC, a iniciar un proceso de desmovilización cuyo límite sea la reincidencia delictiva y criminal. 
Como producto de estos proyectos, ponencias y discusiones surge la Ley 975 de 2005 (julio 25) "Por la cual se dictan disposiciones para la reincorporación de miembros de grupos armados organizados al margen de la ley, que contribuyan de manera efectiva a la consecución de la paz nacional y se dictan otras disposiciones para acuerdos humanitarios".

El debate principal de esta ley se produjo el 13 de mayo de 2005 en la ciudad de Bogotá D. C., allí la presidenta de la Cámara de Representantes, la Dra. Zulema Jattin Corrales expuso que los principios enunciados en el título y contenido de la ley no son elementos retóricos, sino que por el contrario han sido desarrollados por la comunidad internacional en contextos de postconflicto, para consolidar la estructura de la paz y la democracia; de ahí, la necesidad de su inclusión, al tener en cuenta a las víctimas y a la sociedad, por lo que sería erróneo que se argumentara la impunidad de los hechos de violencia perpetrados en el territorio colombiano. Atendiendo a esta configuración normativa expone las dos dimensiones del derecho a la reparación: una individual y otra colectiva, las cuales tienen como fundamento: “(1) La restitución de las cosas a su estado anterior. (2) La indemnización de los perjuicios materiales y morales y (3) La adecuada readaptación de las víctimas, mediante atención psicológica y psiquiátrica” (Ley 975 de 2005).

La senadora Ginna Parody desarrolló su intervención en relación con la reparación, la cual debe incluir garantías de no repetición y de satisfacción de los derechos de las víctimas, como prerrogativa en favor de los bienes jurídicos afectados. Incluye la reparación simbólica como un matiz que permite el fortalecimiento de la memoria colectiva e histórica de los derechos que han sido violados, por lo que dentro de ella se ubicaría: "la aceptación pública de los hechos, el perdón público y el restablecimiento de la dignidad de las víctimas” (Ley 975 de 2005).

El presidente del Colegio de Abogados de Bogotá, Dr. Carlos José Miranda Melo, hizo su intervención señalando que la aplicación universal de esta ley, en el marco de Justicia Transicional no busca favorecer a unos y lesionar a otros, sino que simplemente se busca incluir, dentro en un marco legal, un mecanismo que permita asegurar la reparación de las víctimas y el debido proceso, de lo contrario la cantidad de procesos conllevaría a una prescripción de los delitos, generando impunidad. Este es el sentido de lo que se pretende proteger. 
Ahora bien, si de lo que se trata es de perdonar, conviene recordar [que] en este Estado Social de Derecho, que solamente la Constitución Política, es la norma que permite realmente dar un giro a la situación jurídica del implicado con las características de volver a quedar sin asuntos pendientes por resolver con la justicia. (...) Debemos también recordar que estos procesos deben estar enfocados a una reconciliación en busca de la paz con todos los sectores al margen de la ley para que estos se acojan si lo desean; es decir, que haya igualdad para todos. Consideramos un deber recordar que no se pueden invocar en ningún caso circunstancias de índole espacial o excepcional para castigar a unos y perdonar a otros, porque esto significaría una violación a los derechos y garantías de las personas que no sean llamadas a participar de este proceso. (Ley 975 de 2005)

De esta manera se promulga, publica y aplica la Ley 975 de 2005, Ley de Justicia, Paz y Reparación, la cual instaura la figura del perdón desde dos sentidos: por un lado, se configura en la "alternatividad penal” y, por el otro, en las medidas de reparación, de satisfacción y no repetición como derechos de las víctimas frente a sus victimarios. El primer tipo de perdón constituye una relación Estado-victimario y el segundo se presenta de dos maneras: en las medidas de reparación se establece la relación victimario-víctima, y en las medidas de satisfacción y no repetición, las relaciones victimario-víctima y victimario-sociedad.

El primer tipo de perdón, "Estado-victimario", se configura desde el principio de "alternatividad penal", el cual otorga un beneficio al victimario al suspender de manera cuantitativa la condena por el o los delitos cometidos por una pena privativa de la libertad no menor de 5 años y no superior a 8 años.

Este beneficio se concede a aquellos sujetos que determinó la ley como victimarios ${ }^{1}$, siempre y cuando se comprometan a contribuir con su propia resocialización, mediante procesos pedagógicos. Posteriormente

1 Beneficio de investigación, procesamiento, sanción y beneficios judiciales de las personas vinculadas a grupos armados organizados al margen de la ley, como autores o partícipes de hechos delictivos cometidos durante y con 
al cumplimiento de la pena, el beneficiario se comprometerá a no reincidir en los delitos por los cuales fue condenado durante un periodo temporal que corresponda con la mitad de la pena alternativa cumplida.

Este tipo de perdón se caracteriza por ser un perdón impersonal que hace el Estado en nombre de la sociedad a fin de obtener un proceso rápido y eficaz en la construcción de la verdad, mediante la confesión real y específica de los delitos cometidos, lo que conduce al esclarecimiento de los hechos y a la configuración de la justicia, para lograr una reparación. Bajo este interés se fundamenta el proceso de Justicia Transicional, atendiendo a la necesidad de reconciliación y de paz.

A pesar de la finalidad perseguida, se debe tener en cuenta que esta relación de perdón, impersonal en el sujeto que lo otorga y personal en quien lo recibe, no tiene en cuenta la decisión de la sociedad colombiana de manera directa y específica sobre la materia en la construcción legal, simplemente se toma la decisión de la sociedad de manera indirecta, al momento de elegir a sus senadores, lo cual impide la participación social en la decisión de perdonar a los victimarios.

La construcción filosófica del perdón nos ubicaría en dos posibilidades al momento de examinar esta relación: una expresaría que por ningún motivo puede ubicarse el perdón en esta interacción al encontrarse dentro de la esfera judicial; la otra implicaría la existencia del perdón judicial siempre y cuando comprenda una relación ético-religiosa. La primera posibilidad la argumenta la propuesta filosófica de Derrida, al delimitar el perdón únicamente en una relación intersubjetiva directa, hecho que no ocurre en el escenario de la alternatividad penal, lo que deriva en su inexistencia. Una ampliación de este tema puede consultarse en el capítulo 1 de la presente publicación, así como en la publicación de Niño, Giraldo y Buitrago (2015), que es resultado parcial de los trabajos del proyecto de investigación Políticas del Perdón, desarrollado en la Universidad Santo Tomás.

La segunda posibilidad donde se acepta la existencia del perdón es expresada por Mélich, quien lo ubica en una relación ético-religiosa,

ocasión de la pertenencia a esos grupos, que hubieren decidido desmovilizarse y contribuir decisivamente a la reconciliación nacional. 
sobre lo que no se puede decir pero que sí podemos sentir. En esta línea, trabaja Margalit en dos modelos del perdón, desde donde cabría la justificación del acto de perdonar en la alternatividad penal; están el modelo de eliminar por completo la falta y el del ocultamiento. El primero busca el perdón de Dios para eliminar la existencia histórica de la falta y el segundo busca el perdón con la propuesta final de que esto no se vuelva a nombrar, recordando la existencia en un hecho pasado que no existirá en el futuro, dejándolo en la intimidad divina.

Existe un carácter ético-religioso que aparece ausente en esta relación al no tenerse en cuenta la falta como regularmente lo exigiría el ordenamiento jurídico-penal a fin de eliminar el pasado y de iniciar un proceso de cambio y de conversión, la no reincidencia; lo que nos introduce en la siguiente cuestión ¿Cómo articular el perdón ético-religioso con el perdón político-jurídico? Pregunta que fue analizada en el artículo "El Perdón por Venir", que constituye parte de la misma investigación "Políticas del Perdón en Colombia".

De esta manera, es posible comprender que el Principio de Alternatividad Penal se configura en un tipo de perdón que proviene de una esfera ético-religiosa, donde se pide perdón a fin de no recibir el castigo o que este sea atenuado, compartiendo un margen jurídico-político por la incapacidad del Estado de realizar la totalidad de las investigaciones, lo cual justifica la Justicia Transicional. Esto corresponde con lo expresado por el presidente del Colegio de Abogados durante el debate de aprobación de la Ley 975 de 2005, al afirmar que es preferible aplicar este tipo de medidas político-judiciales, ya que dada la imposibilidad jurídica que tiene el Estado al enfrentarse a numerosas investigaciones, puede terminar en un contexto de prescripción de delitos, y con ello dejar de cumplir las funciones de administrar justicia, reconstrucción de la memoria individual y colectiva, y la reparación a las víctimas.

El segundo tipo de perdón tiene dos manifestaciones: por un lado, la que está enfocada al interior de los actos de reparación de los derechos de las víctimas en la relación victimario-víctima y, por el otro, en las medidas de satisfacción y no repetición donde se genera una relación victimario-sociedad.

En el primer caso, la relación interpersonal excluye al Estado que afirma recurrentemente al interior de la Ley 975 de 2005 que este 
tipo de actos no constituyen aceptaciones de responsabilidad estatal, escondiendo la responsabilidad que tiene como autor de la normatividad en la rama legislativa, y más aún al incluir el perdón como forma de reparación. La petición de perdón en la reparación se encuentra regulada como una forma de reconocimiento público de los daños ocasionados a las víctimas, bien sea desde una simple manifestación pública de arrepentimiento, una solicitud de perdón dirigida a las víctimas y la promesa de no repetición. Esta petición desconoce el carácter espontáneo y personal del perdón, el cual no debe someterse a una regulación normativa de un acto ético, y más aún interferir en la esfera privada del victimario y la víctima, lo que puede generar efectos negativos, destruyendo el sentido del perdón en algunos casos y en otros, imponiéndolo donde no tiene cabida, en lo atroz como hecho imperdonable.

En el segundo caso, las medidas de satisfacción junto con los actos de no repetición se circunscriben en una relación entre victimario-víctima y victimario-sociedad, puesto que en el fondo guardan una promesa como sentido de la petición de perdón. Aunque en la normativa esto aparece como la aceptación de responsabilidades y la petición de disculpas, excluyendo la figura del perdón, nos introduce en la situación impersonal que generaría dicha actuación; sin embargo, al combinarse con la petición de perdón como medida de reparación tiene la implicación de difundir el perdón en una medida de disculpa pública.

Es el caso de la petición de perdón expresada por Mancuso (exlíder paramilitar) que recurre a esta medida, cobijándose con las garantías de la normativa, al expresar una petición de perdón en abstracto a los entes gubernamentales y a las víctimas, sin individualizar a cada una de ellas, con lo que se imposibilita el desarrollo del perdón entre las dos partes que asuma un carácter personal. Incluye en la finalidad del perdón la perspectiva jurídico-estatal del perdón en el acto de la reparación simbólica, y de las garantías de no repetición, al expresar que el fin se circunscribe en evitar el resentimiento, la venganza y en promover el sentido de la paz y la reconciliación, elementos de la filosofía de la Justicia Transicional, y no del acto de la petición del perdón particular.

Este ejemplo narrativo de manifestación de perdón permite evidenciar con claridad los riesgos y problemas que tiene el sentido del perdón al ser incluido en una regulación legislativa y en una aplicación judicial. 
Se examina el beneficio que tiene Mancuso en la disminución de su pena, al ser perdonado por el Estado en su castigo. Aparece la solicitud de perdón como medida de reparación que desarrolla este victimario hacia sus víctimas. Finalmente, se evidencia cómo dicho carácter impersonal se difunde con las medidas de satisfacción y no repetición, al diluirse con las disculpas públicas que surgen en ocasión de este acto; así, se cumple la receta legislativa y judicial a fin de acceder a un beneficio en materia penal, eliminando por completo el sentido ético que tiene el perdón en las relaciones intersubjetivas.

Lo anterior demuestra que en el afán de dar cumplimiento a la administración de justicia de manera rápida, justificándolo desde “supuestos y aparentes" contextos de transición, donde el postconflicto está ausente en el escenario material y real del Estado colombiano, se termina por generar interferencias en escenarios éticos inexistentes, cuyos efectos sobre la población colombiana y en especial en las víctimas es la ausencia de una verdad y una memoria, en un contexto de reparación aparentemente construido, posibilitando la re-victimización en actos conmemorativos como el hecho de pedir perdón.

Ante los problemas que generó esta normativa, las víctimas demandaron la exequibilidad constitucional de la Ley en la Sentencia C-370/06, al exigir la inconstitucionalidad formal de la misma; ello porque estamos ante una ley estatutaria, es decir, aquella que tiene por objeto los derechos humanos, y antes de ser publicada y aplicada debió someterse a un análisis de constitucionalidad por parte de la Corte Constitucional, lo cual no se hizo, y en su contenido material se alegó la falta de un enfoque diferencial, la exclusión de la reparación de las víctimas como sujetos principales. Añaden los demandantes que la ley permite el acceso de los desmovilizados a beneficios sin la obligación de confesar plenamente los hechos delictivos, tal y como es el caso del deber de señalar la ubicación de las personas desaparecidas, al igual que tampoco aparece una sanción o una pérdida de los beneficios por la reincidencia de nuevos delitos, por lo cual se agrede el derecho de las víctimas a la reparación. No obstante, el tema del perdón careció de espacio en el análisis constitucional por parte de los peticionarios y de la Corte, desde el sustento de las repercusiones del marco reparador. 
Ante estas denuncias, la Corte Constitucional desarrolló un juicio de proporcionalidad para determinar la constitucionalidad o inconstitucionalidad de la ley. Es menester aclarar que el juicio de proporcionalidad es una ponderación de dos bienes jurídicos, donde necesariamente se afecta uno de estos para proteger un valor jurídico, por lo que debe partirse de si el fin es constitucionalmente aceptable y, posteriormente, comparar el bien jurídico afectado con el bien jurídico protegido, estableciendo su exequibilidad constitucional.

Por ello, se examinó el derecho a la justicia y el derecho a la paz, marco en el que se afirma un carácter de complementariedad de lo cual no puede alegarse su discrepancia o choque, puesto que se requiere de la justicia para lograr la paz, elementos que no se excluyen al interior de la ley. En ocasiones, pareciera que si ambos bienes jurídicos fuesen afectados o puestos en tensión en procesos de Justicia Transicional, donde se busca pasar de un estado de conflicto a un estado de paz, en el marco de la democracia, allí es necesario generar un beneficio en la imposición de la pena a los sujetos que han causado violaciones a los derechos humanos o infracciones al DIH, a fin de lograr una superación del conflicto armado. Este es el objeto de la Ley 975 de 2005, por lo que no se ha excluido el deber de garantía de los derechos de las víctimas, mediante el establecimiento de un procedimiento penal especial que garantice el derecho a la verdad, a la justicia y a la reparación, conforme al marco de transición. Se incorpora una pena alternativa de 8 años cuyo resultado hasta la fecha son 17 sentencias judiciales que incluyen a 2.000 postulados.

Se obtiene un desarrollo normativo en la Ley 1424 de 2010, conocida como la "Ley de acuerdos de la Verdad", la cual busca que mediante la versión libre se pueda generar un proceso de reconstrucción de la verdad individual, colectiva y judicial, cuyo aporte a la verdad le permita una ejecución condicional de la pena. La Ley 1448 de 2011 expresa una postura política sobre la restitución de las tierras a favor de las víctimas del conflicto armado; allí se regula el principio de solidaridad articulándolo con el deber de reparación y administración judicial en fomento a la restitución de tierras. En el 2012 surge la Ley 1592; se incluye el incidente de reparación judicial, elemento que en su práctica ha presentado graves problemas porque aparece como una reparación meramente administrativa, entrando 
en discusión con una reparación judicial, sin realizar mención alguna sobre la legislación del perdón.

Los proyectos de ley que originaron la regulación de la norma 975 de 2005 que contempla la figura del perdón en tres escenarios: Estado-victimario, victimario-víctima y victimario-sociedad, generaron una sustentación conforme a la necesidad de crear un contexto jurídico-político en el país, desde la Justicia Transicional, donde las garantías judiciales permitieran dar lugar a la verdad y la memoria en el país, a fin de consolidar un escenario de paz, para lo cual se requeriría de la cooperación de los grupos armados al margen de la ley, con lo que se incluyó, dadas las experiencias anteriores, un perdón en materia penal, con la rebaja de penas, desde el Estado colombiano hacia los victimarios, cuyo único límite sería la reincidencia; lo anterior permitiría demostrar la voluntad de paz. Sin embargo, un análisis sobre las implicaciones de una regulación intersubjetiva del perdón, tomando ejemplo de contextos transicionales en otros Estados, resultó ausente, a pesar de haber sido el punto de referencia para la consolidación de un proyecto de ley judicial como es el caso de la Justicia Transicional.

La Ley 975 de 2005 reguló el perdón en tres escenarios, impidiendo la consolidación de una relación interpersonal éticamente responsable sin subordinaciones legales y la consolidación de un marco de veracidad sobre el sentido del perdón. Ya que una regulación de tipo legislativo genera el paso del campo ético de las relaciones interpersonales, a un campo jurídico de relaciones Estado-sociedad-victimario, impidiendo un espacio del perdón al consolidarlo como si se tratara de una receta judicial.

Junto a la aplicación del perdón en la perspectiva judicial, se genera un amplio espacio para una hermenéutica jurídica por parte de los jueces en la aplicación de las medidas, en la reparación de las víctimas y en la verificación del cumplimiento de las sentencias judiciales que al trasladar el perdón al ámbito judicial, terminan por convertirse en árbitros éticos que determinan.

La configuración alterna de un perdón entre victimario-víctima y victimario-sociedad genera la difusión del perdón al conducirlo hacia la disculpa, quedando destruido, puesto que al justificarse una no venganza, se produce un campo para un hecho narrativo disperso e impersonal, como fue el caso de Mancuso. 
En conclusión, la construcción de un marco de justicia que comprenda el perdón crea su imposibilidad real, por lo que al hablarse del perdón en la consolidación normativa debió comprenderse como un efecto de los procesos de justicia transicional por fuera de un marco legal; debió insertarse en un marco exclusivamente político, cuyos efectos éticos, sociales y religiosos se derivaran de una relación interpersonal victimario-víctima, y no como se desarrolló al interior de la ley, donde el Estado es el sujeto activo que representa, regula, normativiza, ordena y verifica la aplicación del perdón en la sociedad colombiana.

El Estado colombiano como dios de la justicia toma en una mano la balanza para mantener el equilibrio social y en la otra, sostiene su espada. Con los ojos vendados, los oídos recubiertos y la voz en alto, no es capaz de percatarse del silencio del perdón... Como si se tratara de un hecho mágico que sonara, que produjera ruido en un espacio en el que solo queda el silencio, olvidando la realidad de la sociedad que se desangra y del sentimiento íntimo y único del victimario que se arrepiente, asumiendo su carga cuando pide perdón.

\section{Referencias}

Teitel, R. (2003). Genealogía de la justicia transicional. Harvard Human Rights Journal, 16, 64-94.

Uprimny, R., \& Saffon, M. P. (2008). Usos y abusos de la justicia transicional en Colombia. En M. Bergsmo \& P. Kalminivitz (Eds.), Law in peace negotiations (pp. 354-400).Oslo: International Peace Research Institute.

\section{Documentos legales}

Ley 975 de 2005. Por la cual se dictan disposiciones para la reincorporación de miembros de grupos armados organizados al margen de la ley, que contribuyan de manera efectiva a la consecución de la paz nacional y se dictan otras disposiciones para acuerdos humanitarios. Julio 25 de 2005. DO. N. ${ }^{\circ} 45980$.

Ley 1424 de 2010. Por la cual se dictan disposiciones de Justicia Transicional que garanticen verdad, justicia y reparación a las víctimas de desmovilizados 
de grupos organizados al margen de la ley, se conceden beneficios jurídicos y se dictan otras disposiciones. Diciembre 29 de 2010. DO. N. ${ }^{\circ} 47937$.

Ley 1448 de 2011. Por la cual se dictan medidas de atención, asistencia y reparación integral a las víctimas del conflicto armado interno y se dictan otras disposiciones. Junio 10 de 2011. DO. N. ${ }^{\circ} 48096$.

Ley 1592 de 2012. Por medio de la cual se introducen modificaciones a la Ley 975 de 2005 "por la cual se dictan disposiciones para la reincorporación de miembros de grupos armados organizados al margen de la ley, que contribuyan de manera efectiva a la consecución de la paz nacional y se dictan otras disposiciones para acuerdos humanitarios" y se dictan otras disposiciones. Diciembre 3 de 2012. DO. N. ${ }^{\circ} 48633$.

Corte Constitucional de Colombia. Sentencia C-579 de 2013. Referencia: Expediente D - 9499. (M. S. Jorge Ignacio Pretelt Chaljub; Agosto 28 de 2013). Acto Legislativo 1 de 2012, "Por medio del cual se establecen instrumentos jurídicos de justicia transicional en el marco del artículo 22 de la Constitución Política y se dictan otras disposiciones", sometido a revisión constitucional.

Proyecto de ley 180 de 2004. Senado. "Por la cual se dictan normas sobre Verdad, Justicia, Reparación, Prevención, Publicidad y Memoria para el sometimiento de los grupos paramilitares que adelanten diálogos con el gobierno". Senadora Piedad Córdoba Ruiz.

Proyecto de ley 208 de 2005. Senado. "Por la cual se dictan disposiciones para la reincorporación de miembros de grupos armados organizados al margen de la ley, que contribuyan de manera efectiva a la consecución de la paz nacional”. Senadores Mario Uribe Escobar y Claudia Blum de Barberi.

Proyecto de ley 209 de 2005. Senado. "Por la cual se establecen las condiciones y procedimientos para la devolución y restitución de bienes entregados por parte de grupos desmovilizados en los procesos de paz". Senador Carlos Moreno de Caro.

Proyecto de ley 210 de 2005. Senado. "Por la paz y la reconciliación nacional (reparación y rehabilitación)". Senador Ricardo Español Suárez.

Proyecto de ley 211 de 2005. Senado. "Ley de Justicia y Paz efectiva a la consecución de la paz nacional por la cual se dictan disposiciones para la reincorporación de miembros de grupos armados organizados al margen de la ley, que contribuyan de manera efectiva a la consecución de la paz nacional". Sabas Pretelt de la Vega, Ministro del Interior y de Justicia. 
Proyecto de ley 212 de 2005. Senado. "Por medio de la cual se dictan disposiciones tendientes a la desmovilización de grupos armados y búsqueda de la reconciliación nacional". 
